\title{
Effect of Temperature on the Chip Soldering Process with AuGa0.03 Alloy Solder
}

\author{
Zhihuan Zhao ${ }^{1,2,3}$, Guanghao Gong ${ }^{1}$, Mingming Jiang ${ }^{2}$, Chuanzhong Chen ${ }^{1,2}, *$, Yingyue Pan ${ }^{2}$, \\ Weili Liu ${ }^{2}$ and Li Zhang ${ }^{3}$ \\ 1 Key Laboratory for Liquid-Solid Structural Evolution and Processing of Materials (Ministry of Education) \\ and Shandong Engineering Research Center for Superhard Material, Department of Materials Science and \\ Engineering, Shandong University, Jinan 250061, China; z2017018@sdaeu.edu.cn (Z.Z.); \\ gong_gh@mail.sdu.edu.cn (G.G.) \\ 2 School of Mechanical and Electronic Engineering, Shandong Agricultural and Engineering University, Jinan \\ 250100, China; z2018008@sdaeu.edu.cn (M.J.); z2013166@sdaeu.edu.cn (Y.P.); z2017006@sdaeu.edu.cn (W.L.) \\ 3 Jinan Semiconductor Research Institute, Jinan 250014, China; 13805313025@163.com \\ * Correspondence: czchen@sdu.edu.cn
}

Received: 17 December 2019; Accepted: 20 January 2020; Published: 22 January 2020

\begin{abstract}
In this study, soldering is conducted between a chip and a CLCC-3 shell base with a sheet-like AuGa0.03 alloy solder as the encapsulating material. X-ray images of chip soldering samples, XRD diffraction analysis of the joints, SEM images reflecting the microstructures of the joints, and EDS of the cross sections of the chip soldering samples show that with gradually increasing soldering temperature, the phase composition is not affected, and all the joint structures are an $\mathrm{Au}+$ $\mathrm{Si}$ eutectic structure; the $\mathrm{Au}-\mathrm{Si}$ eutectic reaction occurs during the soldering process. No deposition of meta-stable phases, such as Au7Si, Au5Si, or Au3S, is found. A soldering temperature of $420{ }^{\circ} \mathrm{C}$ can reduce the negative impacts of secondary cap welding soldering on the joint and improve the structure and mechanical properties of the joint.
\end{abstract}

Keywords: AuGa0.03; soldering temperature; eutectic reaction; eutectic structure

\section{Introduction}

Along with the ongoing development of very large scale integration (VLSI) and miniaturized chip components, the encapsulation and assembly of circuits or systems has been used to realize high performance and the small form factor (SFF) in electronic components and systems [1-4]. Furthermore, the reliability demands on electronic components in the rapidly developing aerospace and avionics industry are increasing. With this trend, hermetically welded seams have been widely used by the military for their high reliability $[5,6]$.

Eutectic soldering is often used in the encapsulation process for its excellent wettability, flowability, processability, physical properties (thermal conductivity and electrical conductivity), chemical properties (anti-corrosion), and mechanical properties (strength, elongation, creep resistance, fatigue resistance, and structure stability) of the solder [7-9]. Gao [10] has used Ti6Al4V and Inconel 718 to solve welding problems, Oliveira [11] has used NiTi to solve weldability problems, and niobium has been used as an interlayer by Oliveira [12] to prevent the formation of brittle phases when joining NiTi to Ti6Al4V. Moreover, for a long period of time, more tin-lead eutectic and hypo-eutectic solders were used for encapsulation; however, lead is a toxic metal element in these solders that is hazardous to humans and the environment [13-17].

To resolve this problem, gold-based solders $[18,19]$ are a good substitution for the encapsulation of semiconductor components. Gold-based solders have anti-corrosion and anti-oxidation properties 
and good fluidity, and are stable under high temperatures. Au-Ga alloy solder [20] is an emerging material in this field, with its higher melting point reducing the negative impact to secondary cap soldering of joints and improving the morphology and mechanical properties.

In this study, with the appropriate time, pressure, and solder-to-chip area ratio and at various soldering temperatures, a connection is made between a chip and a ceramic leaded chip carrier with 3 pins(CLCC-3) shell base [21-23] with an AuGa0.03 solder. In addition, analysis is performed on X-ray images, the microstructure, and the phase composition of the samples.

\section{Experimental}

Soldering was executed between a chip with dimensions $0.38 \mathrm{~mm} \times 0.38 \mathrm{~mm} \times 0.29 \mathrm{~mm}$ and a CLCC-3 shell base with an internal size of $1.78 \mathrm{~mm} \times 1.27 \mathrm{~mm} \times 0.51 \mathrm{~mm}$ by means of a sheet-like $\mathrm{AuGa} 0.03$ alloy solder for commercial use as an encapsulating material. For the welded encapsulation, a domestic deep cavity eutectic soldering station was utilized, where the shell base, solder, and chip were sequentially placed on the station for operation at the five different soldering temperatures, namely, $360^{\circ} \mathrm{C}, 380^{\circ} \mathrm{C}, 400{ }^{\circ} \mathrm{C}, 420^{\circ} \mathrm{C}$, and $440^{\circ} \mathrm{C}$. During the course of the soldering, the solder-to-chip area ratio, soldering time, and pressure were set as $1.2,15 \mathrm{~s}$, and $20 \mathrm{~g}$, respectively.

The shear strength of the joint was tested by a shear force tester. An X-ray detection system was used to observe the macro-morphology of the samples. The phase composition of the joint was analyzed using XRD. A scanning electron microscope equipped with an energy-disperse spectrometer (EDS) attachment was used to study micro-morphology and element distributions of the samples.

\section{Results}

In this experiment, a domestic deep-cavity eutectic soldering table which was independently developed was adopted; it was equipped with a temperature control function (maximum working temperature $600{ }^{\circ} \mathrm{C} \pm 0.5^{\circ} \mathrm{C}$ ), nitrogen and hydrogen gas protection function, ultrasonic function, and foot pressure function as shown in Figure 1. A platinum-rhodium thermocouple with high stability was used to measure the temperature of the heating surface, and then the temperature was controlled by the deep-cavity eutectic soldering table.

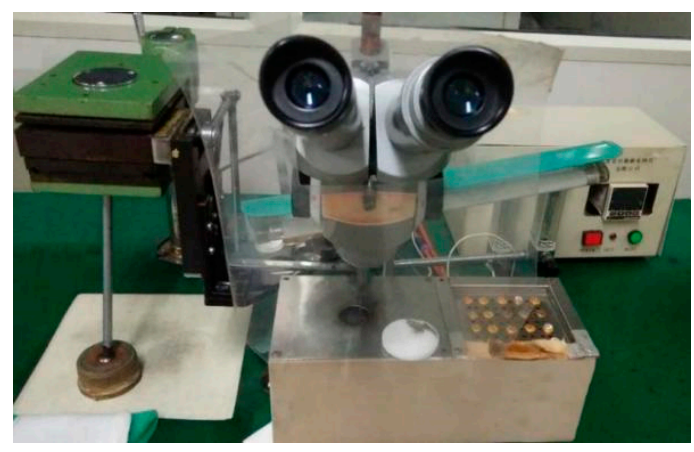

Figure 1. Deep-cavity eutectic soldering table.

When the soldering temperatures were $360^{\circ} \mathrm{C}, 380^{\circ} \mathrm{C}, 400{ }^{\circ} \mathrm{C}, 420{ }^{\circ} \mathrm{C}$, and $440{ }^{\circ} \mathrm{C}$ the maximum shear strengths of the chip soldering joints were $5.23 \mathrm{~N}, 7.52 \mathrm{~N}, 9.25 \mathrm{~N}, 11.23 \mathrm{~N}$, and $6.71 \mathrm{~N}$, respectively. When the soldering temperature increased gradually, the AuGa0.03 solder could be melted more thoroughly, and thus it was more helpful to wet and spread the solder over the surface of the chip to form a tight connection. Furthermore, the shear strength of the welded joint was increased as well. However, if the temperature was too high, the joint shear strength dropped dramatically, which was attributed to overburning. X-ray images of the chip soldering samples by different soldering temperatures are shown in Figure 2 and cross-section morphologies of the samples are shown in Figure 3. 


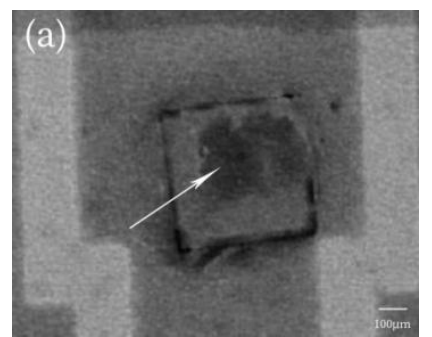

(a)

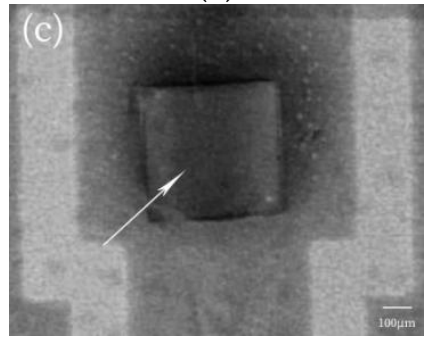

(c)

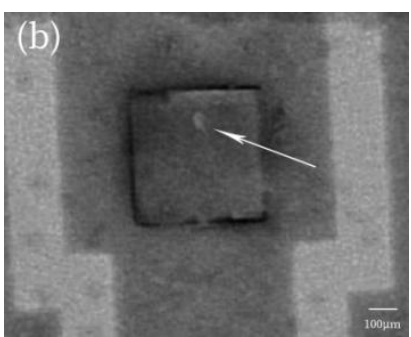

(b)

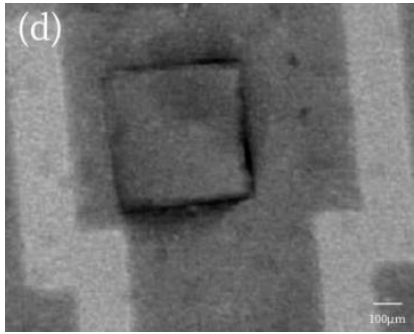

(d)

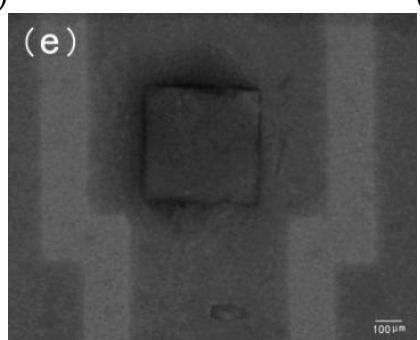

(e)

Figure 2. Photos of the samples at different soldering temperatures: $360{ }^{\circ} \mathrm{C}(\mathbf{a}), 380{ }^{\circ} \mathrm{C}(\mathbf{b}), 400{ }^{\circ} \mathrm{C}(\mathbf{c})$, $420{ }^{\circ} \mathrm{C}(\mathbf{d})$, and $440{ }^{\circ} \mathrm{C}(\mathbf{e})$.

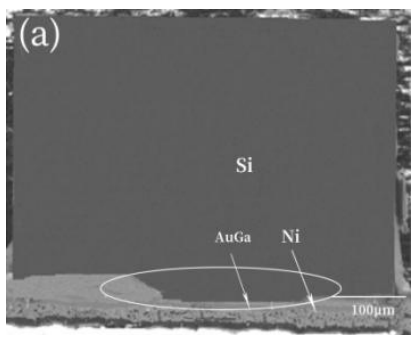

(a)

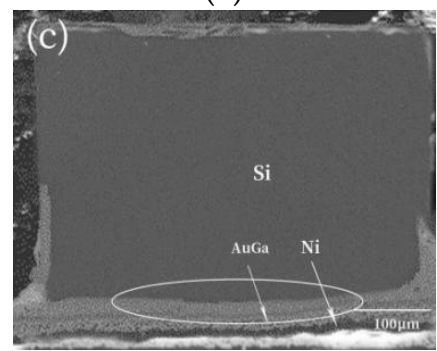

(c)

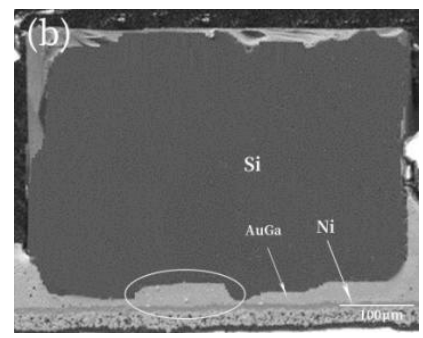

(b)

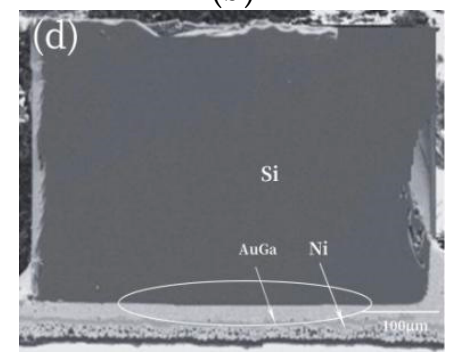

(d)

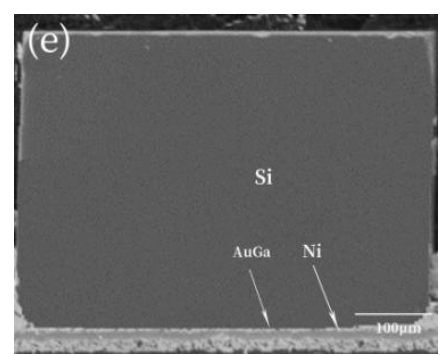

(e)

Figure 3. Cross-section morphologies of the samples at different soldering temperatures: $360{ }^{\circ} \mathrm{C}(\mathbf{a})$, $380^{\circ} \mathrm{C}(\mathbf{b}), 400{ }^{\circ} \mathrm{C}(\mathbf{c}), 420^{\circ} \mathrm{C}(\mathbf{d})$, and $440{ }^{\circ} \mathrm{C}(\mathbf{e})$.

Through Figures 2 and 3 it can be understood that at the soldering temperature of $360{ }^{\circ} \mathrm{C}$, the $\mathrm{AuGa} 0.03$ solder was not melted sufficiently due to the low temperature; in addition, the spreading of the solder over the surface of the chip was unsatisfactory, and holes appeared. When the temperature increased, the solder was melted more fully, causing better wetting of the surface to occur. The quality 
of the welded joint was fairly good, but the higher the temperature the more holes which were observed at the joint due to overburning.

\section{Discussion}

An Au-Si phase diagram is shown in Figure 4 [24]. It shows that that $\mathrm{Au}$ and $\mathrm{Si}$ are not mutually soluble and that no compound is generated. The eutectic temperature is $363 \pm 2{ }^{\circ} \mathrm{C}$ and the eutectic point is $19.0 \pm 0.5 \%$. Au-Si is basically a combination of physics except for a few coherent grains. In the process of soldering, $\mathrm{Au}$ and Si diffused mutually at a high temperature, forming the soldering interface, and there is an obvious crystal orientation when $\mathrm{Si}$ is diffused into Au.

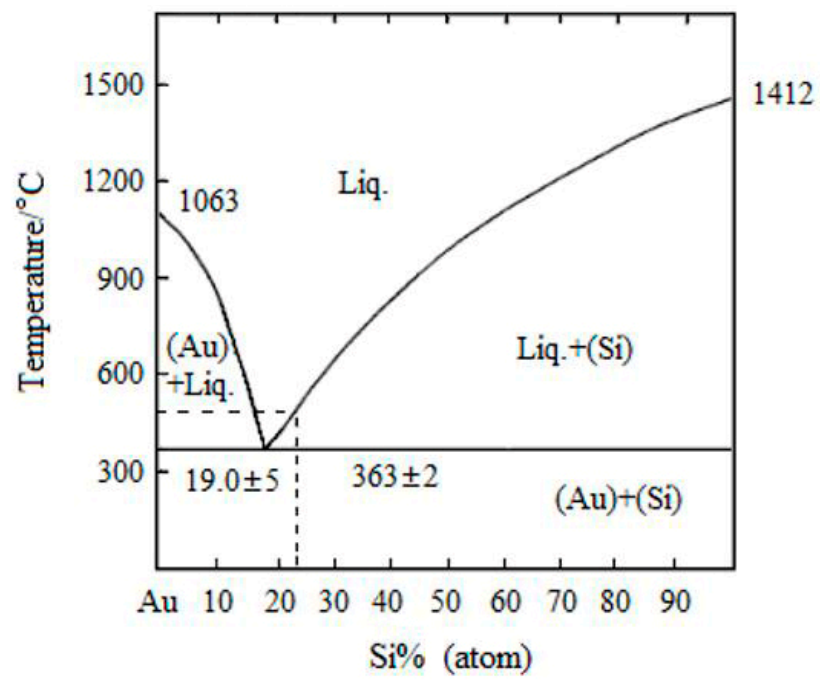

Figure 4. Au-Si phase diagram [24]. Legend: Liq., liquid.

XRD diffraction of the joints at different soldering temperatures is shown in Figure 5. The analysis shows that the composition of the joint is primarily $\mathrm{Au}$ and $\mathrm{Si}$ and that the phase compositions of the joints at different temperatures are exactly the same; only the relative intensities of the diffraction peaks vary. No diffraction peaks from meta-stable phases such as Au7Si, Au5Si, and Au3Si are observed due to the relatively high soldering temperatures (all higher than the Au-Si eutectic temperature), and the meta-stable phase decomposition results in a primary phase of $\mathrm{Au}$ and $\mathrm{Si}$ which is favorable for stability and joint strength. The Au-Si eutectic reaction of Equation (1) [25] occurs mainly in the course of chip eutectic soldering.

$$
\mathrm{L} \rightarrow \mathrm{Au}+\mathrm{Si}
$$

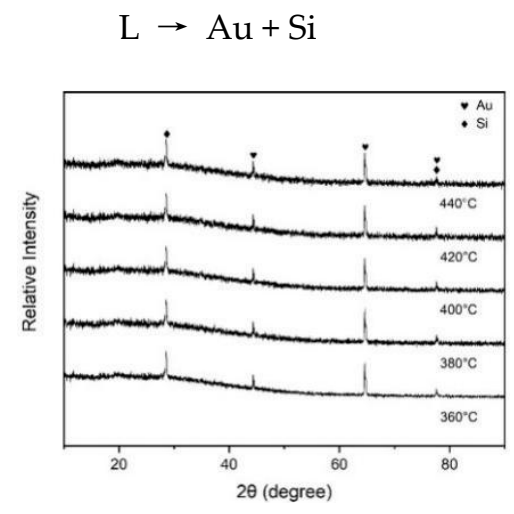

Figure 5. Patterns of joints at different soldering temperatures. 
Figure 6 shows SEM images reflecting the microstructures of joints at the various soldering temperatures. The joint close to the chip has an $\mathrm{Au}+\mathrm{Si}$ eutectic structure, no compounds formed from other metals, and some holes distributed therein due to the large density difference between the Au-Si liquid phase $(18.64 \mathrm{~g} / \mathrm{cm} 3)$ and $\mathrm{Si}(2.33 \mathrm{~g} / \mathrm{cm} 3)$. The volume consumed by the Si reaction cannot be compensated by the $\mathrm{Au}-\mathrm{Si}$ eutectic liquid phase formed during the bonding process. On the other hand, there is a large volume shrinkage and high thermal stress in the Au-Si liquid phase. The figure shows that when the soldering temperatures are $360^{\circ} \mathrm{C}$ and $380^{\circ} \mathrm{C}$, a number of large holes appear in the joint; most of the holes are approximately channel-type with a width of around $1 \mu \mathrm{m}$ and a length of approximately $5 \sim 6 \mu \mathrm{m}$. These hole formations are due to the low temperature. The AuGa0.03 solder is not sufficiently melted at low temperature, and the poor wetting and spreading of the solder on the surface of the chip leads to insufficient density in the structure. When the soldering temperature is $400{ }^{\circ} \mathrm{C}$ the occurrence of channel cavities in the joint decreases. Because the soldering temperature has not reached the process temperature, there are occasionally some large holes; when the soldering temperature is $400{ }^{\circ} \mathrm{C}$, small honeycomb holes are scattered mostly surrounding the joints, and, occasionally, some large holes are not present. The solders can be melted thoroughly and wet the chip well at this process temperature, and the joint structure is denser. However, when the temperature reaches $440^{\circ} \mathrm{C}$, the solder melts rapidly due to the relatively high temperature and cannot form a good and dense connection with the chip. The width of the soldering seam is small, and more large holes are visible.
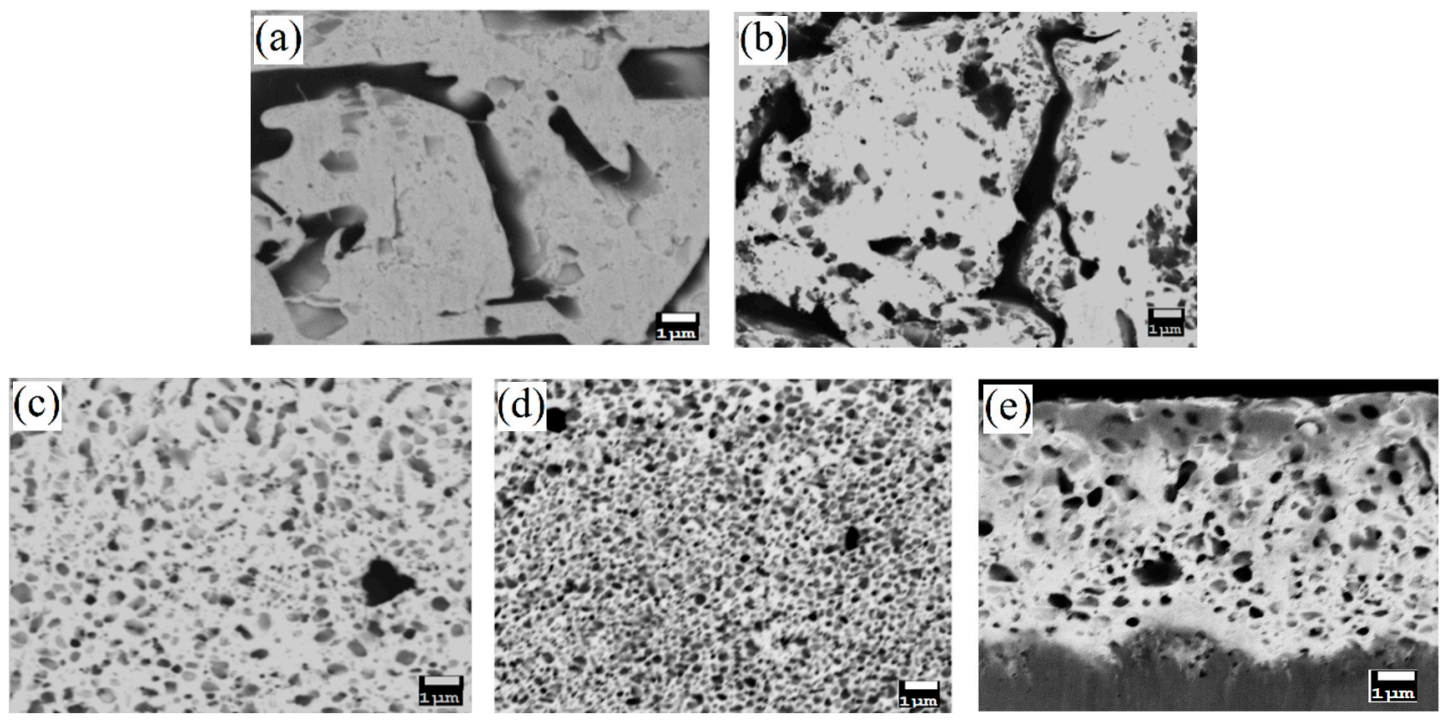

Figure 6. SEM images of joints at different soldering temperatures: $360{ }^{\circ} \mathrm{C}(\mathbf{a}), 380{ }^{\circ} \mathrm{C}(\mathbf{b}), 400{ }^{\circ} \mathrm{C}(\mathbf{c})$, $420{ }^{\circ} \mathrm{C}(\mathbf{d})$, and $440{ }^{\circ} \mathrm{C}(\mathbf{e})$.

The cross sections of the chip samples soldered at the different temperatures were analyzed by energy-dispersive spectroscopy. The areas selected for line scanning and EDS spectral analysis are shown in Figure 7, and reveal that during the soldering process, Au and Si diffuse at a high temperature to form a soldering interface. Diffusion soldering was conducted with the AuGa0.03 solder on the top layer of the silicon-based chip. The thickness of the inter diffusion is approximately $2 \mu \mathrm{m}$ at low temperatures, whereas the thickness of the inter diffusion is approximately $4 \mu \mathrm{m}$ at $440{ }^{\circ} \mathrm{C}$. One or more peaks of silicon were found in the sample by this testing after the first low point reached by the $\mathrm{Si}$ diffused in the AuGa0.03 solder. These peaks were produced because in the joint there are several pits filled with Si powder from the preparation of the sample. The joint should be the eutectic of $\mathrm{Au}$ and $\mathrm{Si}$ and the AuGa0.03 solder contained in each sample was melted from a finished product of $50 \mu \mathrm{m}$ to a thickness of approximately $20 \mu \mathrm{m}$, but Ga was not detected by EDS because the composition of Ga was 
extremely low. Through soldering, a eutectic reaction occurred between the gold protective layer over the surface of the base and the AuGa0.03 solder.
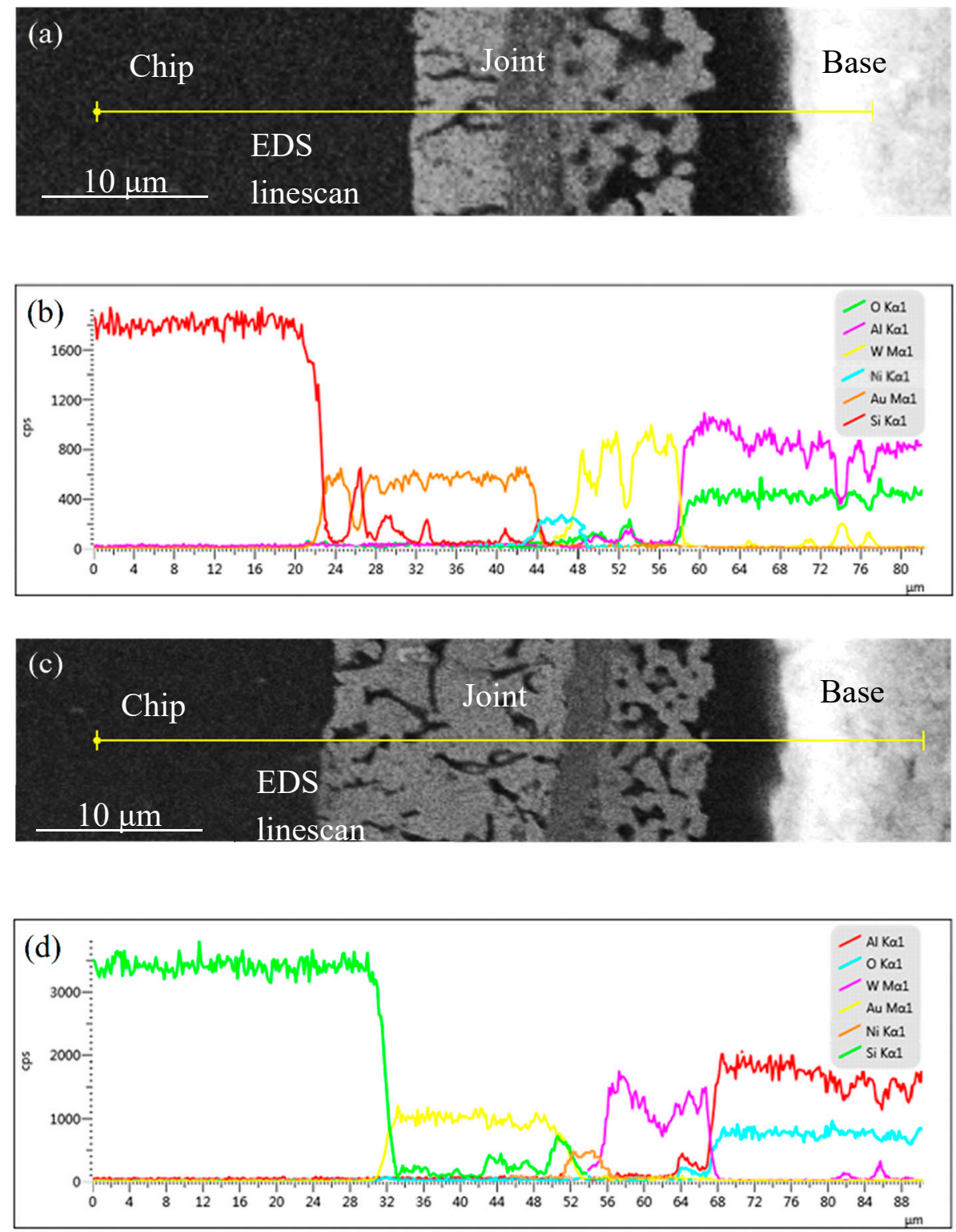

Figure 7. Cont. 

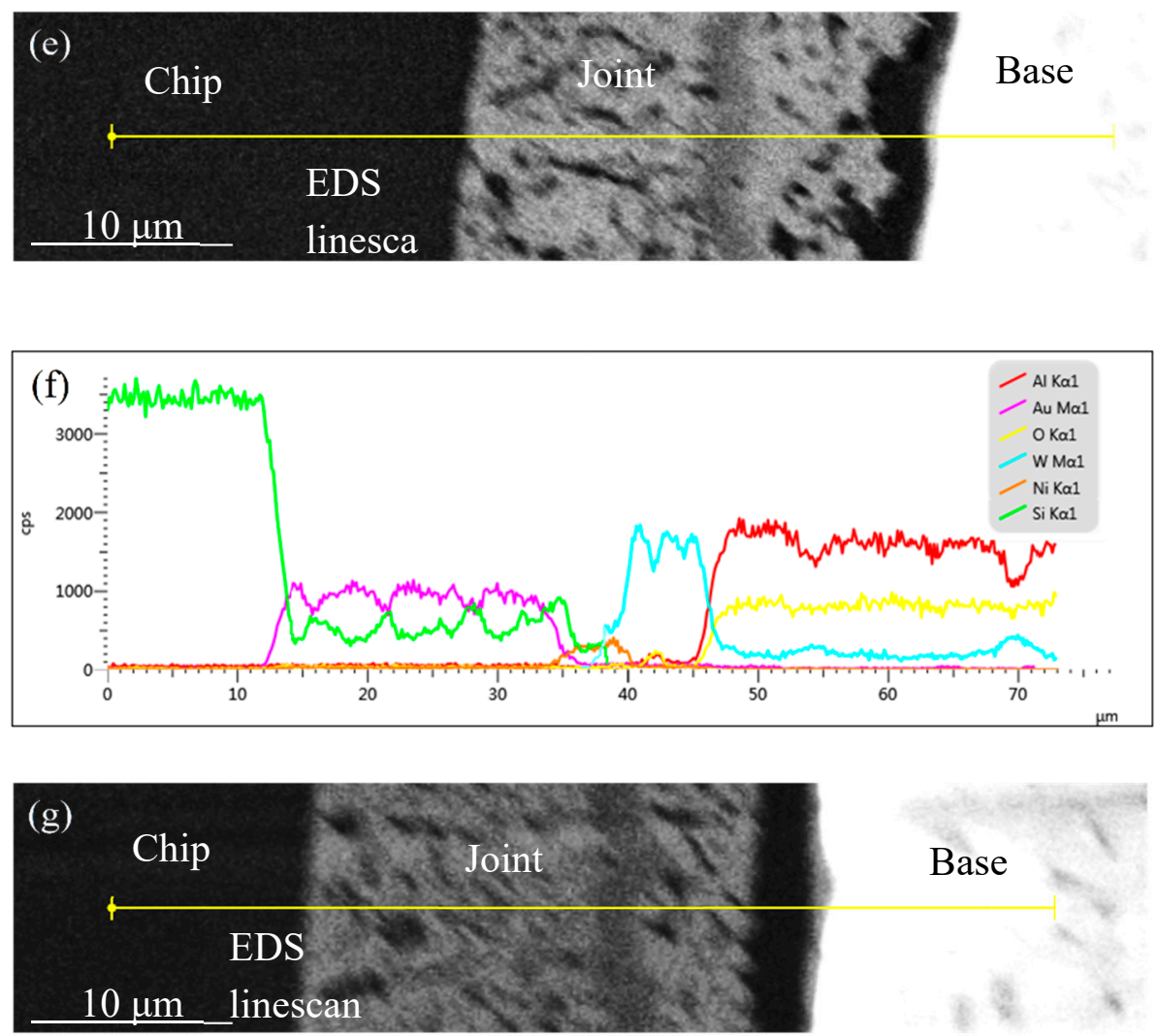

Base
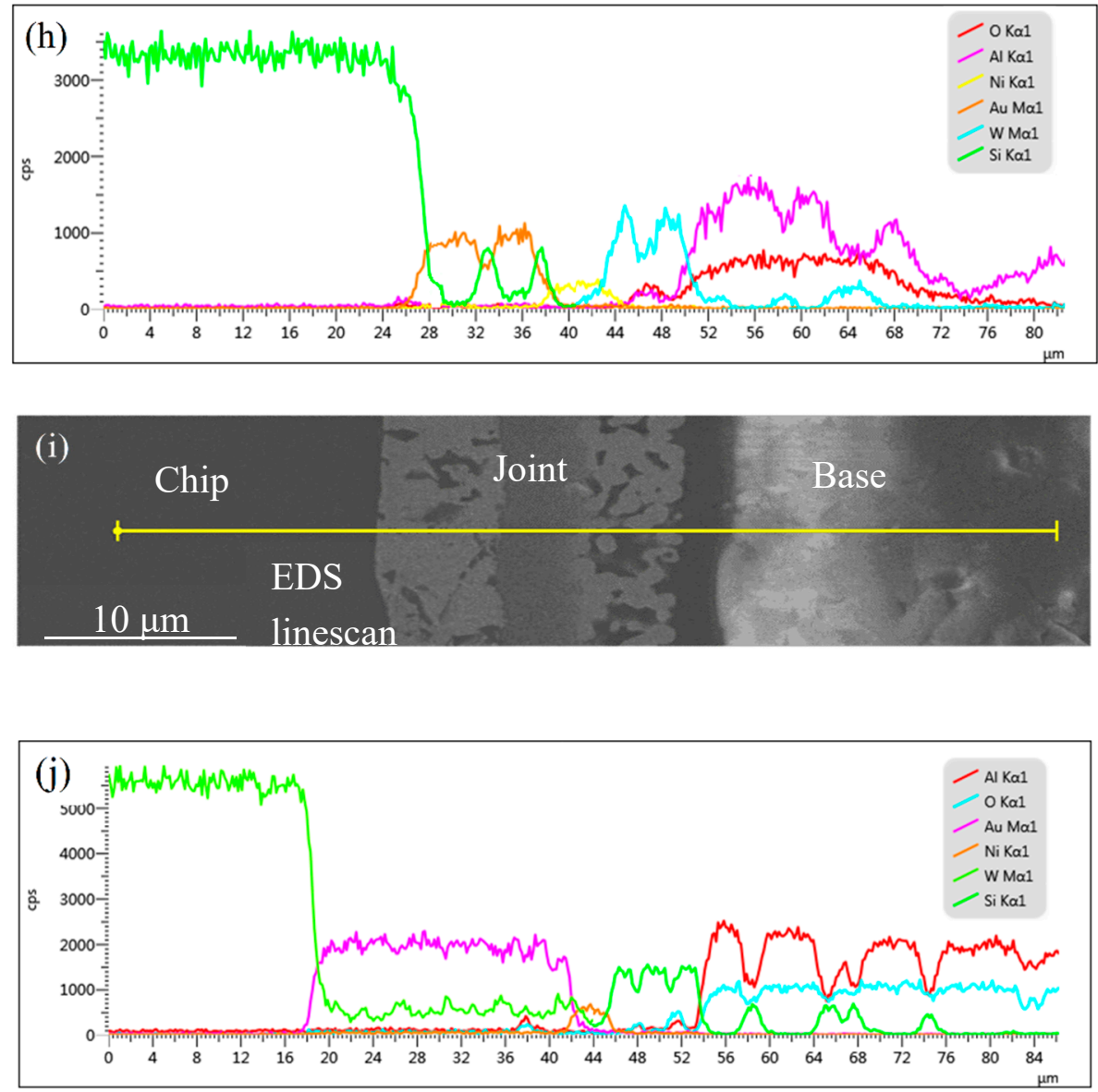

Figure 7. SEM morphology and energy-dispersive spectroscopy (EDS) line-scan of samples welded at $360^{\circ} \mathrm{C}(\mathbf{a}, \mathbf{b})$ and $380{ }^{\circ} \mathrm{C}(\mathbf{c}, \mathbf{d})$. SEM morphology and EDS line-scan of samples welded at $400{ }^{\circ} \mathrm{C}(\mathbf{e}, \mathbf{f})$, $420^{\circ} \mathrm{C}(\mathbf{g}, \mathbf{h})$, and $440^{\circ} \mathrm{C}(\mathbf{i}, \mathbf{j})$. 
According to the specific temperature parameters, 20 samples were taken for comparison, and the corresponding shear strengths of the corresponding chips are shown in Table 1.

Table 1. Chip soldering test program at different temperatures.

\begin{tabular}{ccc}
\hline $\begin{array}{c}\text { Group } \\
\text { No. }\end{array}$ & $\begin{array}{c}\text { Temperature } \\
\left({ }^{\circ} \mathbf{C}\right)\end{array}$ & $\begin{array}{c}\text { Maximum Shear Force } \\
(\mathbf{N})\end{array}$ \\
\hline T1 & 360 & 5.23 \\
T2 & 380 & 7.52 \\
T3 & 400 & 9.25 \\
T4 & 420 & 10.12 \\
T5 & 440 & 6.71 \\
\hline
\end{tabular}

With the increase in soldering temperature, the AuGa0.03 solder melts more fully, spreads more easily on the chip surface, and then forms a close connection, and the shear strength of the welded joint also increases. However, when the temperature is too high, the shear strength of the joint drops sharply, which may be caused by overburning in the soldering process. When the soldering temperature is 400 ${ }^{\circ} \mathrm{C}$ the chip has the best welding strength and its maximum shear force can reach $10.12 \mathrm{~N}$, and it can not only meet the internal structure requirements but also far exceed the shear strength standard of $2 \mathrm{n}$ under the chip area, which can meet the shear strength requirements of chip welding.

\section{Conclusions}

In this study, the results show that the shear strength of a joint can be influenced by the soldering temperature through affecting the microstructure of the joint. The phase composition is not affected by the change in the soldering temperature and all the joint structures are an $\mathrm{Au}+\mathrm{Si}$ eutectic structure, while the Au-Si eutectic reaction occurs during the soldering process. No deposition of meta-stable phases, such as Au7Si, Au5Si, and Au3Si, etc., is found, and thus, it is helpful to the stability to enhance the joint strength. When the soldering temperature is increased gradually, the $\mathrm{Au}+\mathrm{Si}$ eutectic structure gets denser and denser, and the original channel-type large holes in the structure are transformed into diffusely distributed honeycomb-like fine holes, which can improve the mechanical properties.

Author Contributions: Conceptualization, Z.Z., G.G., C.C.; methodology, Z.Z., G.G.; investigation, Z.Z., G.G., Y.P., W.L. and M.J.; data curation, Z.Z. and G.G.; formal analysis, Z.Z., G.G., M.J., C.C. and Y.P.; validation, W.L. and L.Z.; visualization, W.L. and L.Z.; writing-original draft preparation, Z.Z. and G.G.; writing-review and editing, Z.Z., and G.G.; project administration, C.C.; supervision, C.C. All authors have read and agreed to the published version of the manuscript.

Funding: This research was funded by the Key R \& D project of Shandong Province, grant number 2018 GGX101014 and 2018CXGC0811.

Conflicts of Interest: The authors declare no conflict of interest.

\section{References}

1. Wang, X.G.; Ren, H.Y.; Zhu, M.; Li, R.D.; Shu, H.L. The research of $\beta$-SiCp/Al electronic packaging composites fabricated by pressureless infiltrating. Adv. Mater. Res. 2012, 490, 3816-3821. [CrossRef]

2. Haeper, C.A. Electronic Materials and Processes Handbook, 3rd ed.; McGraw-Hill: New York, NY, USA, 2005; pp. 88-92.

3. Arai, H. Integrated Circuit, 2nd ed.; Science Press: Beijing, China, 2000; pp. 51-60.

4. Shi, Y.W.; Xia, Z.D.; Chen, Z.G.; Lei, Y.P. New Advances in Solders Research for Electronic Assembly. Electronics Process Technology 2001, 22(4), 139-143.

5. Rabaey, J.M.; Chandrakasan, A.; Nikolic, B. Digital Integrated Circuits: A Design Perspective, 2nd ed.; Publishing House of Electronics Industry: Beijing, China, 2004; pp. 35-40.

6. Baliga, B.J. The future of power semiconductor device technology. Proc. IEEE 2002, 89, 822-832. [CrossRef]

7. Tang, T.; Zhang, X.; Xu, Z.Z.J. Research progress and trends of electronic packaging materials. J. Nanjing Univ. Technol. Nat. Sci. Ed. 2010, 32, 105-110. (in Chinese). 
8. Xiu, Z.Y.; Zhang, Q.; Wu, G.H.; Song, M.H.; Zhu, D.Z. AlSiC metal matrix composites and its application in microelectronics packaging. Electron. Packag. 2006, 6, 16.

9. Huang, M.L.; Pan, J.L.; Ma, H.T.; Zhao, N. Interfacial reactions of sequentially electroplated Au/Sn/Au films on Si chips. Mater. Sci. Technol. 2012, 28, 837-843. [CrossRef]

10. Gao, X.L. Dissimilar metal welding of Ti6Al4V and Inconel 718 through pulsed laser welding-induced eutectic reaction technology. Int. J. Adv. Manuf. Technol. 2018, 96, 1061-1071. [CrossRef]

11. Oliveira, J.P.; Miranda, R.M.; Braz Fernandes, F.M. Welding and joining of NiTi shape memory alloys: A review. Prog. Mater. Sci. 2017, 88, 412-466. [CrossRef]

12. Oliveira, J.P. Laser joining of NiTi to Ti6Al4V using a Niobium interlayer. Acta Mater. 2016, 105, 9-15. [CrossRef]

13. Cheng, S.; Huang, C.M.; Pecht, M. A review of lead-free solders for electronics applications. Microelectron. Reliab. 2017, 75, 77-95. [CrossRef]

14. Bath, J.; Handwerker, C.; Bradley, E. Lead-free solder alternatives. Circuits Assembly. 2000, 5, 31-40.

15. Lee, N.C. A thorough look at lead-free solder alternatives. Circuits Assembly. 1998, 4, 64-71.

16. Cary, H.B.; Helzer, S.C. Modern Welding Technology, 2nd ed.; Chemical Industry Press Co., Ltd.: Beijing, China, 2010; pp. 1-26.

17. Richards, B.P. Lead-Free Legislation, 1st ed.; National Physical Laboratory: London, UK, 2002; pp. 11-15.

18. Chung, H.M.; Chen, C.M.; Lin, C.P.; Chen, C.J. Microstructural evolution of the Au-20 wt.\% Sn solder on the Cu substrate during reflow. J. Alloy. Compd. 2009, 485, 219-224. [CrossRef]

19. Zhou, T.; Bobal, T.; Oud, M.; Jia, S.L. An Introduction to Eutectic Au/Sn Solder Alloy and Its Preforms in Microelectronics/Optoelectronic Packaging Applications. Electron EPackag. 2005, 5, 5.

20. Liu, J.M.; Guo, C.P.; Li, C.R.; Du, Z.M. Thermodynamic assessment of the Au-Ga system. J. Alloy. Compd. 2010, 508, 62-70. [CrossRef]

21. Goswami, A.P.; Roy, S.; Das, G.C. Effect of powder, chemistry and morphology on the dielectric properties of liquid-phase-sintered alumina. Ceram. Int. 2002, 28, 439-445. [CrossRef]

22. Yin, Y.S.; Zhang, J.D. Alumina Ceramics and Their Composites, 2nd ed.; Chemical Industry Press Co., Ltd.: Beijing, China, 2001; pp. 93-102. (in Chinese)

23. Zhang, Y.H.; Zhang, P.; Zhou, Y.B.; Wang, J.L. Application and Latest Development of Ceramic Colorants. Ceramics 2000, 5, 25-27. (in Chinese).

24. Chao, B.; Chae, S.H.; Zhang, X.F.; Lu, K.H.; Im, J.; Ho, P.S. Investigation of diffusion and electromigration parameters for $\mathrm{Cu}-\mathrm{Sn}$ intermetallic compounds in $\mathrm{Pb}$-free solders using simulated annealing. Acta Materialia 2007, 55, 2805-2810. [CrossRef]

25. Gan, H.; Choi, W.J.; Xu, Q.; Tu, K.N. Electromigration in solder joints and solder lines. J. Electron. Mater. 2002, 54, 34-37.

(C) 2020 by the authors. Licensee MDPI, Basel, Switzerland. This article is an open access article distributed under the terms and conditions of the Creative Commons Attribution (CC BY) license (http://creativecommons.org/licenses/by/4.0/). 